\title{
Seamless Reconstruction of Intact Adult-Born Neurons by Serial End-Block Imaging Reveals Complex Axonal Guidance and Development in the Adult Hippocampus
}

\author{
Gerald J. Sun, ${ }^{1,2 \star}$ Kurt A. Sailor, ${ }^{1,2,4 \star}$ Qasim A. Mahmood, ${ }^{1}$ Nikhil Chavali, ${ }^{1}$ Kimberly M. Christian, ${ }^{1,3}$ Hongjun Song, ${ }^{1,2,3,4}$ \\ and Guo-li Ming $1,2,3,4$ \\ ${ }^{1}$ Institute for Cell Engineering, ${ }^{2}$ The Solomon H. Snyder Department of Neuroscience, and ${ }^{3}$ Department of Neurology, Johns Hopkins University School of \\ Medicine, Baltimore, Maryland 21205, and ${ }^{4}$ Diana Helis Henry Medical Research Foundation, New Orleans, Louisiana 70130-2685
}

In the adult mammalian hippocampus, newborn dentate granule cells are continuously integrated into the existing circuitry and contribute to specific brain functions. Little is known about the axonal development of these newborn neurons in the adult brain due to technological challenges that have prohibited large-scale reconstruction of long, thin, and complex axonal processes within the mature nervous system. Here, using a new serial end-block imaging (SEBI) technique, we seamlessly reconstructed axonal and dendritic processes of intact individual retrovirus-labeled newborn granule cells at different developmental stages in the young adult mouse hippocampus. We found that adult-born dentate granule cells exhibit tortuous, yet highly stereotyped, axonal projections to CA3 hippocampal subregions. Primary axonal projections of cohorts of new neurons born around the same time organize into laminar patterns with staggered terminations that stack along the septo-temporal hippocampal axis. Analysis of individual newborn neuron development further defined an initial phase of rapid axonal and dendritic growth within $21 \mathrm{~d}$ after newborn neuron birth, followed by minimal growth of primary axonal and whole dendritic processes through the last time point examined at $77 \mathrm{~d}$. Our results suggest that axonal development and targeting is a highly orchestrated, precise process in the adult brain. These findings demonstrate a striking regenerative capacity of the mature CNS to support long-distance growth and guidance of neuronal axons. Our SEBI approach can be broadly applied for analysis of intact, complex neuronal projections in limitless tissue volume.

\section{Introduction}

The adult mammalian hippocampus undergoes remarkable structural plasticity whereby new dentate granule cells are continuously generated and integrated into the existing circuitry (Ming and Song, 2011). Cumulative evidence suggests contributions of newborn neurons to specific hippocampal functions, attributed partly to special properties that arise transiently during their development and maturation (Ge et al., 2007; Aimone et al., 2011; Sahay et al., 2011; Gu et al., 2012; Marín-Burgin et al.,

Received April 1, 2013; revised May 12, 2013; accepted May 21, 2013.

Author contributions: G.J.S., K.A.S., H.S., and G.-I.M. designed research; G.J.S., K.A.S., Q.A.M., N.C., and K.M.C. performed research; G.J.S., K.A.S., Q.A.M., N.C., and G.-I.M. analyzed data; G.J.S., K.A.S., K.M.C., H.S., and G.I.M. wrote the paper.

This work was supported by National Institute of Health grants NS048271, HD069184 (G.-I.M.), NS047344, MH087874, ES021957 (H.S.), and NS066612 (K.A.S.); Dr. Miriam and Sheldon G. Adelson Medical Research Foundation (G.-I.M.); SFARI (H.S.); Brain and Behavior Research Foundation (G.-I.M. and K.M.C.); and Children's Tumor Foundation (G.J.S.). We thank T. Sailor for designing and manufacturing the imaging stage setup and T. Shelly for manufacturing the sectioning stage, C. Zhong and S. Pupkin for help, members of Ming and Song laboratories for discussion, and L. Liu and Y. Cai for technical support. We acknowledge the joint participation by the Diana Helis Henry Medical Research Foundation through its direct engagement in the continuous active conduct of medical research in conjunction with The Johns Hopkins Hospital and the Johns Hopkins University School of Medicine and the Foundation's Parkinson's Disease Program No. H-1 (G.-I.M.).

${ }^{*}$ G.J.S. and K.A.S. contributed equally to this work.

The authors declare no competing financial interests.

Correspondence should be addressed to Dr. Guo-li Ming, Institute for Cell Engineering, Johns Hopkins University School of Medicine, 733 North Broadway, MRB 779, Baltimore, MD 21205. E-mail: gming1@jhmi.edu.

DOI:10.1523/JNEUROSCI.1374-13.2013

Copyright $\odot 2013$ the authors $\quad 0270-6474 / 13 / 3311400-12 \$ 15.00 / 0$
2012). How new neurons directly impact hippocampal function is not well understood, in part because there is little knowledge about the spatial extent and development of their efferent projections. Understanding basic features of adult-born granule cell development may not only provide novel insight into fundamental principles of neuronal development and function of adult neurogenesis, but also strategies for cell replacement therapy in the mature nervous system.

Proper guidance of a developing axon to its target is an essential step of circuit formation. Significant progress has been made in the last two decades in deciphering axon guidance processes, including growth, targeting, and fasciculation in the developing nervous system (Tessier-Lavigne and Goodman, 1996). In the adult rodent hippocampus, studies using nucleotide analog or onco-retrovirus labeling have demonstrated that newborn granule neurons rapidly extend their axons to the CA3 region and form morphologically and functionally characteristic mossy fiber bouton synapses (Hastings and Gould, 1999; Markakis and Gage, 1999; Zhao et al., 2006; Faulkner et al., 2008; Toni et al., 2008; Gu et al., 2012). In these early studies, however, complex axonal processes became fragmented in histological slices; and tissue loss and distortion from sectioning prevented faithful serial reconstruction of individual thin, long axons (Luzzati et al., 2011). As a result, we know very little about axonal guidance and development of newborn neurons in the adult brain. The relationship of axonal to dendritic development of individual newborn neurons 
and among different newborn neurons is also unknown. Knowledge of full neuronal structure and development will provide a better understanding of new neuron function in the adult brain. Such information would be also invaluable for understanding neurological disorders, such as epilepsy and schizophrenia, in which adult-born granule axonal development is thought to be greatly altered (Faulkner et al., 2008; Kron et al., 2010; Zhou et al., 2013).

To elucidate the structure and development of intact adultborn granule cells in vivo, we developed a novel method of serial sectioning and imaging, termed serial end-block imaging (SEBI), for seamless reconstruction of unlimited tissue volume. We characterized axonal and dendritic development of newborn neurons in the adult mouse hippocampus between 10 and $77 \mathrm{~d}$ after retroviral labeling. We found that axons of newborn neurons follow a highly stereotyped, tortuous path from the dentate gyrus through the CA3 subfields and exhibit regular laminar organization along the hippocampal septo-temporal axis. Furthermore, rapid primary axonal process and dendritic development occurs within the first $21 \mathrm{~d}$. Our study provides novel insights into adult neurogenesis and demonstrates a striking capacity of the mature brain environment to support long-distance growth and guidance of neuronal axons.

\section{Materials and Methods}

Stereotaxic virus injection and tissue processing. Engineered murine onco-retrovirus containing green fluorescent protein (GFP) or GFPtagged Channelrhodopsin $2 \mathrm{cDNA}$ and Woodchuck hepatitis posttranscriptional regulatory element, both driven by the Ubiquitin-C promoter, were generated as previously described (Ge et al., 2006; Duan et al., 2007; Kim et al., 2012). High titers of retrovirus were stereotaxically injected into the dentate gyrus of 8 -week-old C57BL/6 female mice (Charles River) using a Nanoject II microinjection glass pipette (Drummond Scientific) at four sites ( $0.5 \mu \mathrm{l}$ per site) with a 5-10 $\mu \mathrm{m}$ tip using the following coordinates from bregma $(\mathrm{mm})$ : anterior-posterior (AP) -2.0 , lateral \pm 1.6 , ventral -1.6 ; AP -3.0 , lateral \pm 2.5 , ventral -1.8 . All animal procedures followed approved institutional protocols.

At 10, 17, 21, 35, 56, and $77 \mathrm{~d}$ post-injection (dpi) of retrovirus, mice ( $n=2,1,2,2,1,2$, respectively) were perfused with $4 \%$ paraformaldehyde (PFA) and brains were postfixed in PFA overnight. Brains were then transferred to $\mathrm{PBS}$ with $0.02 \%$ sodium azide and stored at $4^{\circ} \mathrm{C}$. One to 2 $\mathrm{mm}$ of tissue was removed from the lateral portion of the posterior cerebral cortex and cerebellum at $\sim 15^{\circ}$ angle to provide a flat surface for mounting. The brain was then separated at the midline into hemispheres and cyanoacrylate glued to a $2 \mathrm{~mm}$ agarose disc on the posterior $15^{\circ}$ mounting surface of the brain, which translates into a $15^{\circ}$ cut angle off the sagittal plane for serial imaging/sectioning. The sample was then placed in a 6-well culture dish and covered with $2 \%$ agarose (Sigma-Aldrich) in saline. The tissue-containing gel cube was glued to the base of a vibrating microtome chamber. The chamber was rinsed and filled with normal saline for the imaging procedure.

Serial imaging and vibrating microtome sectioning. The tissue block was imaged using an upright confocal microscope (LSM 510; Carl Zeiss) with a two-photon laser (Chameleon; Coherent) tuned to $910 \mathrm{~nm}$ and a $20 \times$ 1.0 NA water-dipping objective (Carl Zeiss) using a tile scan (8-bit, 0.88 $\mu \mathrm{m} \times 0.88 \mu \mathrm{m} \times 2 \mu \mathrm{m}$ ) with a $10 \%$ overlap. Once imaged at a $z$-depth of $120 \mu \mathrm{m}$, the tissue block was sectioned with a sapphire blade (121-18; Ted Pella) at a depth of $60 \mu \mathrm{m}$ using a vibrating microtome with digital $z$-indexing (VT1200; Leica Microsystems). The sections were collected and stored in PBS with $0.02 \%$ sodium azide. The procedure was repeated until the tissue was sectioned and imaged in its entirety (see Fig. 1A,B). Images were acquired with sufficient overlap in all three dimensions (50\% in $z$-axis, $10 \%$ in $x, y$-axis) for computer-guided tissue volume reconstruction.

The chamber was reproducibly positioned on the microscope and vibrating microtome stages using modified hardware, consisting of an aluminum plate with three conical holes and two linear slots that were machined and mated with the chamber (Fig. 1C). A microscope stage adapter was also manufactured with three 3/8-inch tooling balls (McMaster-Carr) that matched the conical hole dimensions of the chamber to provide accurate, reproducible chamber positioning on the microscope stage. Metal rails were attached to the vibrating microtome stage; these mated with the linear slots of the chamber for accurate positioning and reproducible sectioning on the vibrating microtome.

Volume reconstruction of hippocampus via rigid-body transformation. Acquired images were aligned for volume reconstruction in XuvStitch software (Emmenlauer et al., 2009). XuvStitch calculates and uses only rigid-body transformations; the software outputs aligned image volumes and the associated $x, y, z$ coordinates used for alignment. Blind or guided alignment algorithms can be used by the software, with increased memory usage and ability to robustly align arbitrary images for the blind algorithm.

Each imaged tissue section, or "slab," consisted of tiled cubes with $10 \%$ $x, y$-overlap between adjacent within-slab cubes and $50 \%$ overlap between those of previous or successive slabs. Image slabs were first split into their constitutive tiled cubes. One cube from each imaged slab was paired with its $z$-overlapping counterpart from a successive slab, loaded into XuvStitch, and $x, y, z$ alignment coordinates were collected from blind, "exhaustive search" stitching (Fig. 1D). These coordinates were propagated to all cubes within a respective slab to yield a theoretical alignment of all cubes from all slabs. The propagated coordinates were then loaded, along with their associated cubes, into XuvStitch for final alignment using the memory-efficient guided, "current coordinate" alignment algorithm (Fig. 1D).

Image deconvolution and normalization. To correct for imaging artifacts (e.g., $z$-spreading) inherent to laser-scanning microscopy, 3D deconvolution was performed on the reconstructed hippocampus volumes (Autoquant; MediaCybernetics). Inherent to imaging through opaque tissue, there was a significant decay of signal intensity with increasing imaging depth. In addition, acquisition parameters varied depending on strength of fluorescent signal and alignment and power output of the multiphoton imaging laser throughout the multiday SEBI acquisition process. $Z$-slices within a given reconstructed hippocampus volume were therefore quantile normalized. Originally used to normalize identical features across replicates of microarray chips (Bolstad et al., 2003), quantile normalization preserves relative intensity values within an image, while normalizing intensities between images. Quantile normalization produced both qualitatively (Fig. $1 E$ ) and quantitatively (Fig. $1 F$ ) uniform intensity across the $z$-axis in the volume of tissue.

Neuronal structure tracing and quantification. The complete granule cell structure was traced using the FilamentTracer module in Imaris (Bitplane) software on a computer containing a Quadro 5000 (Nvidia) video card with 3D Vision (Nvidia) stereoscopic visualization. Threedimensional glasses were used to visualize the large datasets and the autodepth and/or autopath tracing modes were used for tracing. In addition, the orthoslicer feature was used to visualize the $2 \mathrm{D}$ data to discriminate difficult-to-resolve structures. The complete dendritic structure and primary branch of axons of individual GFP ${ }^{+}$granule cells were traced. Given a previous report of differential developmental rates of newborn neurons in the septal and temporal hippocampus (Piatti et al., 2011), only traced cells in the septal half of the hippocampus were used for quantitative analysis of primary axonal length and total dendritic length ( 3,8 cells at $10 \mathrm{dpi} ; 0$ cells at $17 \mathrm{dpi} ; 11,3$ cells at $21 \mathrm{dpi} ; 10$, 3 cells at $35 \mathrm{dpi} ; 15$ cells at $56 \mathrm{dpi}$; and 6, 7 cells at $77 \mathrm{dpi}$; cell numbers are listed per mouse) and these cells were combined with additional cells traced from the temporal half for analysis of organization of axonal projections within cohorts of adult-born granule cells along the septotemporal axis $(n=5$ cells at $77 \mathrm{dpi}$; see Fig. $3 D)$. Axon collaterals were excluded from analyses due to their thin $(<0.2 \mu \mathrm{m})$ (Claiborne et al., 1986) and highly convoluted, overlapping structure that precluded reliable tracing with our imaging resolution and GFP brightness. In accordance with previous anatomical characterizations, axon boutons were 
A

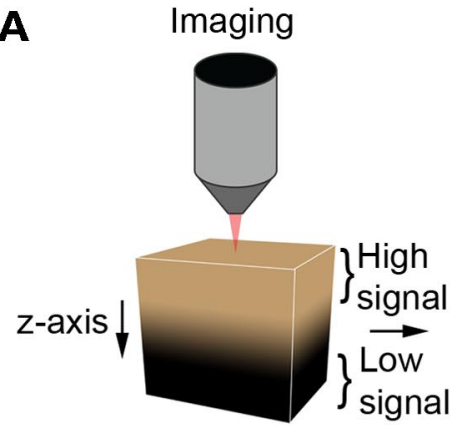

C

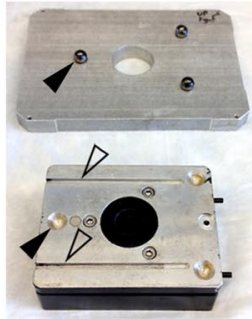

Chamber
Reconstruction
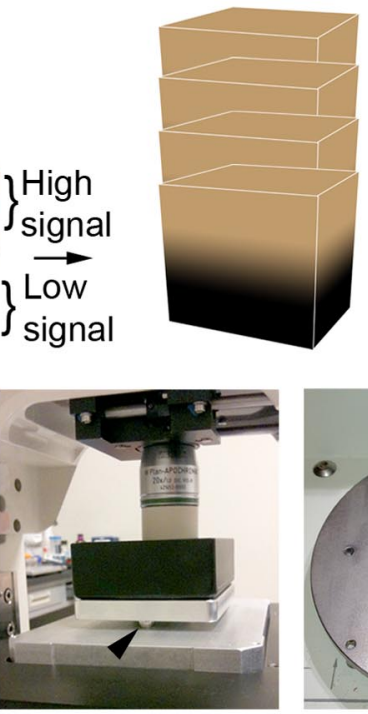

Imaging stage

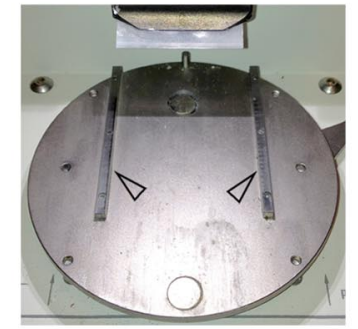

Sectioning stage
B

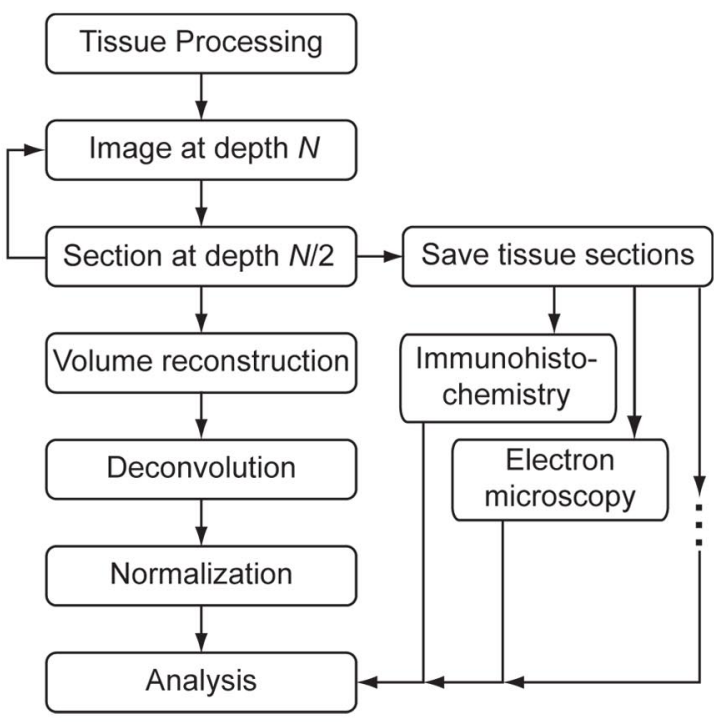

D

High signal
over

low signal

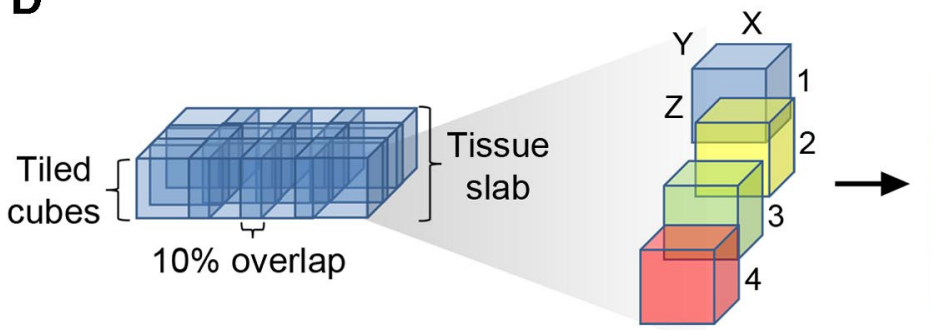

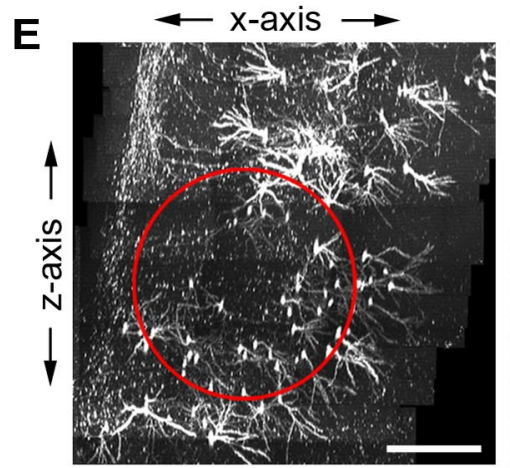

Before normalization

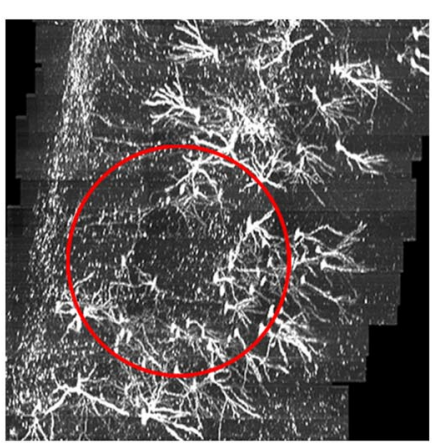

Normalized

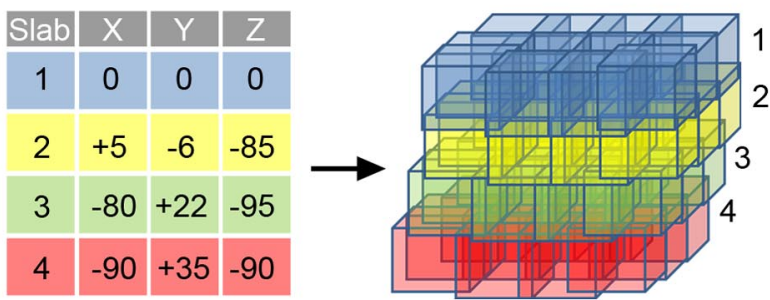

F

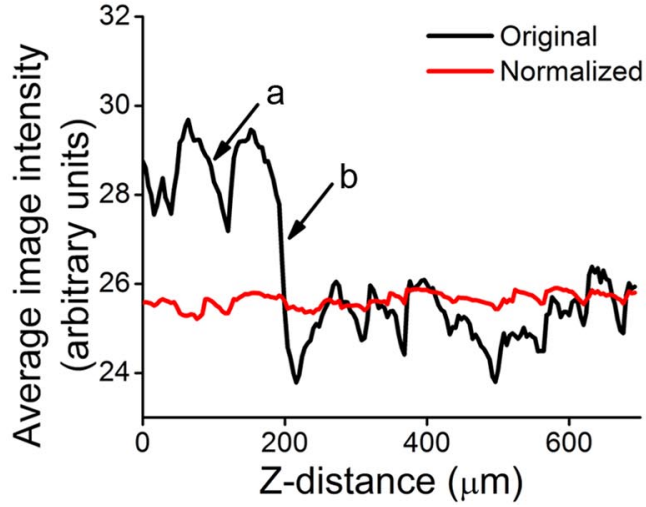

Figure 1. SEBl imaging paradigm, image reconstruction technique, and normalization. $A$, SEBl imaging paradigm to obtain optimal image quality of intact tissue: tissue of interest (depicted by a brown cube) is end-block imaged, sectioned, and serially reconstructed by overlaying high-quality signal within the superficial layers on top of the lower quality signal within deep regions. $\boldsymbol{B}$, $A$ schematic diagram of SEBI procedure. C, Tissue chamber with conical holes (filled arrows) and slots (open arrows) that mates with imaging and sectioning stages for reproducible positioning. $\boldsymbol{D}$, Image reconstruction technique (from left to right): end-block imaging yields an imaged tissue slab array of $10 \%$-overlapping tiled cubes. Cubes in adjacent slabs are used to determine $x, y, z$-offset values. Offsets are then propagated to all cubes within the dataset to allow for complete volume stitching and seamless reconstruction. $E$, Sample $X$-Z projection image of unprocessed reconstructed adult hippocampus with high signal intensity variation (red circle, left image), and subsequent uniform signal intensity after quantile normalization (red circle, right image). Scale bar, $300 \mu \mathrm{m} . \boldsymbol{F}$, Plot of intensity change versusz-depth of reconstructed hippocampus subregion in $\boldsymbol{E}$ before (black line) and after (red line) normalization. Note that before normalization, intensity variability existed within a tissue slab (a) and between imaging sessions (b).

defined as puncta directly connected to the axonal structure with a diameter $>3 \mu \mathrm{m}$ (Henze et al., 2000). Similar to axon collaterals, axon boutons $<3 \mu \mathrm{m}$ in diameter, although numerous and important (Claiborne et al., 1986), were excluded from analyses due to their small size, which precluded reliable identification with our imaging resolution and GFP brightness.

Sholl analysis (in 3D) for assessing dendritic complexity was performed in Imaris and neuronal structure parameters were exported to an Excel spreadsheet. Total dendrite length was reported as the sum of all dendrite branches; axon length was reported as the length of only the single primary axon branch. Statistical analyses were performed using one-way ANOVA with a Tukey post hoc test in OriginPro Software (OriginLab) and the two-sample Kolmogorov-Smirnov test in MATLAB (MathWorks). Correlation was calculated in MATLAB and reported as a Pearson's correlation coefficient, $R^{2}$, with an associated $p$ value calculated using Student's $t$ test. Ordinary least-squares linear regressions and associated SEM, 95\% confidence intervals, and $p$ values were calculated using multiple linear regression analysis and a 

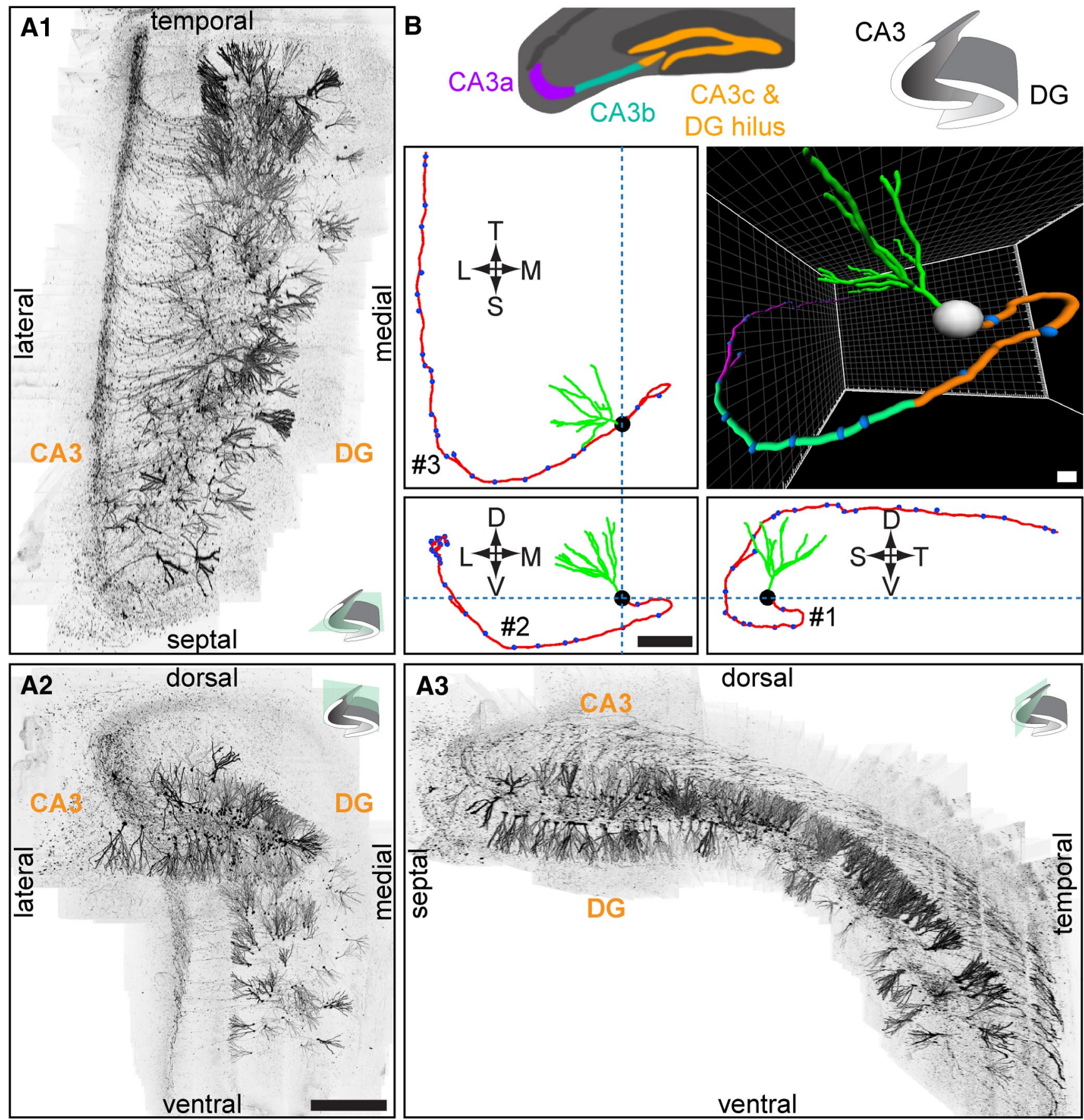

Figure 2. Complete reconstruction of intact adult mouse hippocampus with SEBI. $A$, Complete reconstruction of retrovirally labeled GFP ${ }^{+}$newborn granule neurons (at $77 \mathrm{dpi)}$ ) in the adult mouse hippocampus projected onto horizontal (A $)$, coronal (A2), and sagittal (A3) planes, with respect to the hippocampal axis as indicated. See also Movie 1. DG, dentate gyrus. Scale bar, $500 \mu \mathrm{m}$. $\boldsymbol{B}$, Sample tracing of a single adult-born granule cell at 56 dpi shown in the same orientations as in $A$, with CA3 subregions color-coded for CA3c (orange), CA3b (green), and CA3a (purple), as defined by Lorente de Nó (1934). Primary axon projections of adult-born granule cells make as many as three distinct turns: (\#1) up to $180^{\circ}$ within the hilus, (\#2) a ventral to dorsal turn within CA3b, and (\#3) a longitudinal turn toward the temporal pole within CA3a. T, temporal; S, septal; L, lateral; M, medial; D, dorsal; V, ventral. Scale bar, $150 \mu \mathrm{m}$.

bootstrapping procedure in MATLAB. For data where $x$ values were not experimentally fixed, ordinary least products regression was used.

Axon stacking was defined as the instance when an axon from a more septal granule cell projected dorsally over a neighboring axon from a more temporal granule cell (Fig. 3D). Axon staggering was defined as the instance when an axon from a more septal $\mathrm{GFP}^{+}$granule cell terminated before that of a more temporal $\mathrm{GFP}^{+}$granule cell along the septotemporal axis. Both axon traits were quantified on a per cell basis across cells from adjacent transverse planes. Cells that violated either pattern were quantified only once to prevent spurious classifications upon comparison with other cells.

\section{Results}

SEBI of intact cellular structure: whole hippocampus and axonal trajectory of adult-born dentate granule cells

To reconstruct the complete, fine primary axonal processes of adult-born dentate granule cells in the intact hippocampus, we 
developed a serial imaging and sectioning method, named SEBI. The fundamental principle underlying SEBI is to oversample imaging of intact tissue along the $z$-axis and reconstruct complete tissue volumes by overlaying high-quality signal from superficial layers onto lower quality signal from deep layers of successively imaged tissue (Fig. 1A). SEBI is achieved by serially imaging and then sectioning of a tissue block end-face (Fig. $1 B$ ). Block endface imaging ensures that fully intact cellular structures are acquired in their native conformation. Utilizing a simple tissue chamber alignment apparatus (Fig. 1C), serial sectioning was highly reproducible. Because tissue slices are collected throughout the SEBI procedure, SEBI enables potential post hoc analysis with immunohistochemistry, electron microscopy, or other techniques (Fig. 1B). Importantly, we have also incorporated existing software and established a simple, effective means for rapid large volume reconstruction and image normalization to correct for significant decay of signal intensity with increasing imaging depth (Fig. 1E,F). Together, our SEBI technology provides a robust, flexible, and easily implemented method of imaging complete, intact cellular structure in essentially unlimited tissue volume.

We first applied the SEBI approach to examine the complete structure of GFP-labeled mature adult-born hippocampal dentate granule cells at 56-77 dpi. We successfully reconstructed the entire mouse hippocampus and could, for the first time, visualize and trace the intact axonal primary projection to CA3 and complete dendritic processes of individual newborn neurons across the hippocampal septo-temporal axis (Fig. 2A; Movie 1). When annotating axon projection patterns, the CA3 region was subdivided into three subdomains (CA3a, CA3b, CA3c; Fig. 2B) in accordance with characterization by Lorente de Nó (1934). While projecting through the dentate gyrus hilar region toward CA3c, $\mathrm{GFP}^{+}$axons turned at an angle whose magnitude varied depending on the axon's parent soma location (range $=0-180^{\circ}$; Fig. $2 B$, $\# 1$ ). After projecting through the hilus and $\mathrm{CA} 3 \mathrm{c}$ region, all axons analyzed exhibited a second, $90^{\circ}$ turn from ventral to dorsal, as they traversed the CA3b subregion (Fig. 2B, \#2). Turns \#1 and \#2 occurred precisely in the transverse hippocampal plane. Finally, upon entering CA3a, all axons analyzed exhibited a third, $90^{\circ}$ turn, projecting toward the temporal pole of the hippocampus (Fig. 2B, \#3). This complex axonal projection trajectory was highly stereotyped across all mature adult-born granule cells examined $(n=33)$ and may be present in all mature adult-born granule cells along the septo-temporal hippocampal axis. These results suggest a highly regulated axon-targeting process in the adult CNS.

\section{Characteristic axonal targeting and growth of individual newborn granule cells in the adult hippocampus}

Having observed a stereotyped axon trajectory of mature adultborn granule cells, we next examined whether axons of newborn neurons follow such a tortuous path and target CA3 precisely throughout the course of their development. Two-month-old mice were injected with GFP-expressing retrovirus and examined at $10,17,21,35,56$, and $77 \mathrm{dpi}$. All GFP ${ }^{+}$neurons exhibited a single axon from the cell body. Across all developmental time points examined, axons followed a very stereotypical path through the hilus and into CA3 (Fig. 3A). At 10 dpi, axons exhibited only the initial turn in the hilar region and projected as far as CA3b. No evidence of multiple growth cones was observed, suggesting that axons are precisely targeted. By $17 \mathrm{dpi}$, most axons made both hilar and CA3b turns, and by $21 \mathrm{dpi}$, axons had made all three stereotypical turns and projected into CA3a. Beyond 21

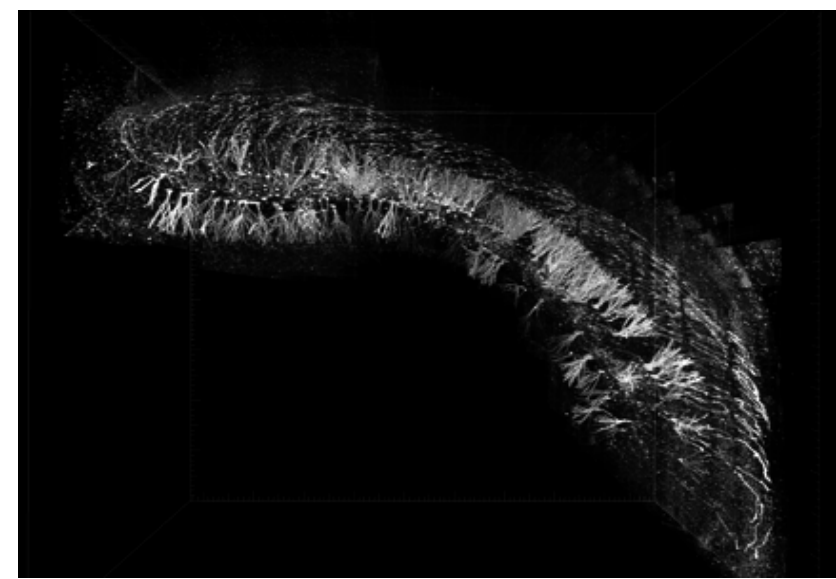

Movie 1. Septal to temporal fly-through of complete hippocampus reconstruction showing the full structure of retrovirally labeled GFP ${ }^{+}$newborn granule cells (77 dpi; see the same reconstruction in Fig. 2A).

dpi, the primary axon projection patterns remained unchanged. These results suggest that developing axons of newborn granule cells follow their final projection path in the adult hippocampus.

Quantification of primary axon length of adult-born granule cells revealed two distinct developmental phases. During the initial phase from 10-21 dpi, axons rapidly increased their length (Fig. 3B). This first growth phase exactly matched the developmental window in which axons targeted and traversed through all CA3 subregions. Primary axonal length appeared to exhibit minimal change during a second phase from 21 to $77 \mathrm{dpi}$, a time when adult-born granule cells can evoke stable synaptic responses in CA3 (Gu et al., 2012). At 77 dpi, primary axons of adult-born dentate granule neurons exhibited an average length of $\sim 1.9 \mathrm{~mm}$ with the longest traced axon observed at $2.3 \mathrm{~mm}$ (Fig. $3 B$ ). Notably, our measurement represents an underestimation of total axonal length of adult-born neurons, as our analyses omitted their numerous, fine axon collaterals. Together, these results demonstrate that newborn neurons can extend very long axonal projections in an otherwise highly inhibitory adult CNS environment for regenerating axons of mature neurons.

\section{Highly organized axonal projections within cohorts of adult-born granule cells}

After characterizing axon growth and targeting of individual neurons, we next addressed whether any organizational patterns or lamination existed among cohorts of developing adult-born granule cells. During adult hippocampal neurogenesis, newborn neurons arise from adult neural stem cells via transient cell amplification stages, thus our $\mathrm{GFP}^{+}$cells represented cohorts of sister new neurons born around the same time (Bonaguidi et al., 2012). When comparing neighboring $\mathrm{GFP}^{+}$neurons at a given time point (between 21 and $77 \mathrm{dpi}$ ), we observed a highly regular lamination pattern in the CA3a region (Fig. $3 D$ ). Approximately $90 \%(45 / 50)$ of traced axons originating from more septal neurons (Fig. $3 C, D, c$ ) stacked dorsally on top of those from more temporally positioned neurons (Fig. $3 C, D, b$ ). We also observed staggering of axon termination points in the CA3 region, whereby $84 \%$ (42/50) of traced axons from more septal neurons terminated sooner than those from more temporal neurons (Fig. $3 D, i)$. This organization was present throughout the septotemporal axis and independent of total axonal length of adultborn neurons. Finally, hilar axon segments differed in curvature depending on the granule cell soma location across the dentate 

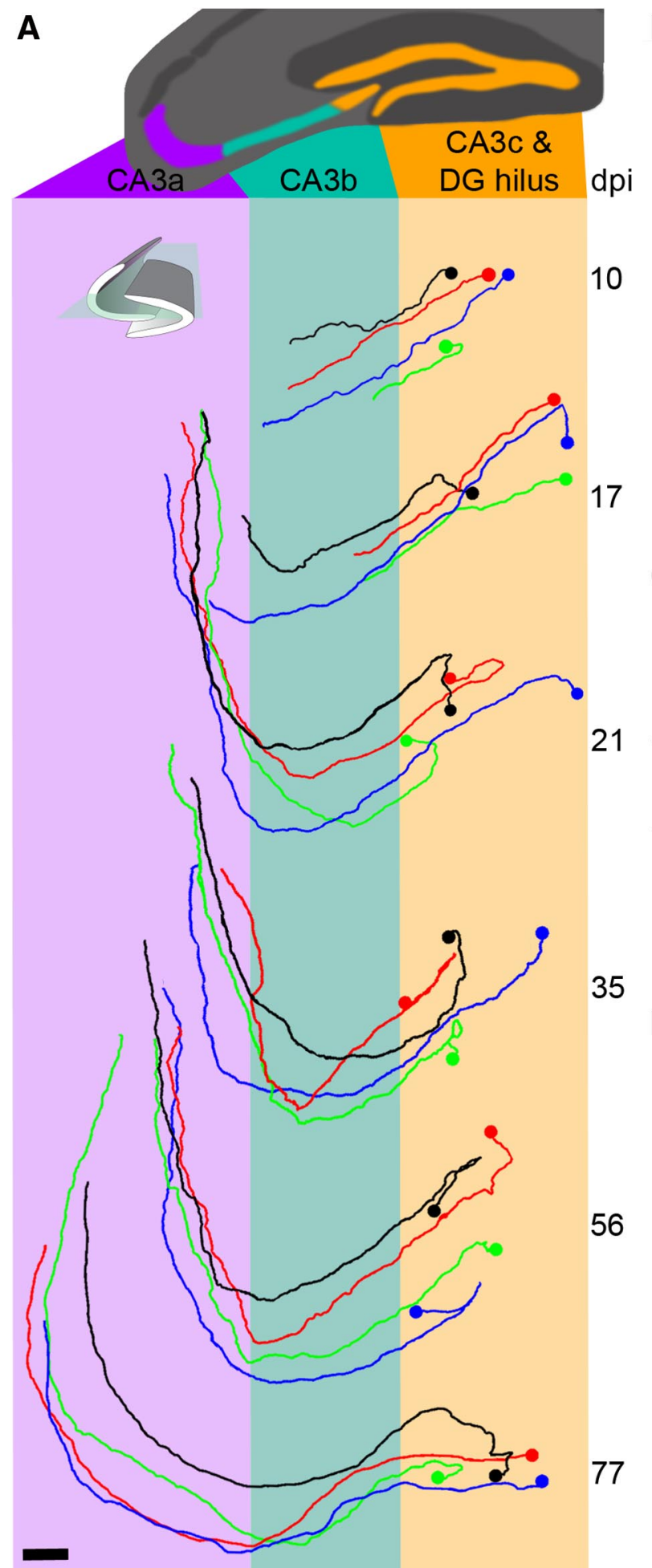

35
B

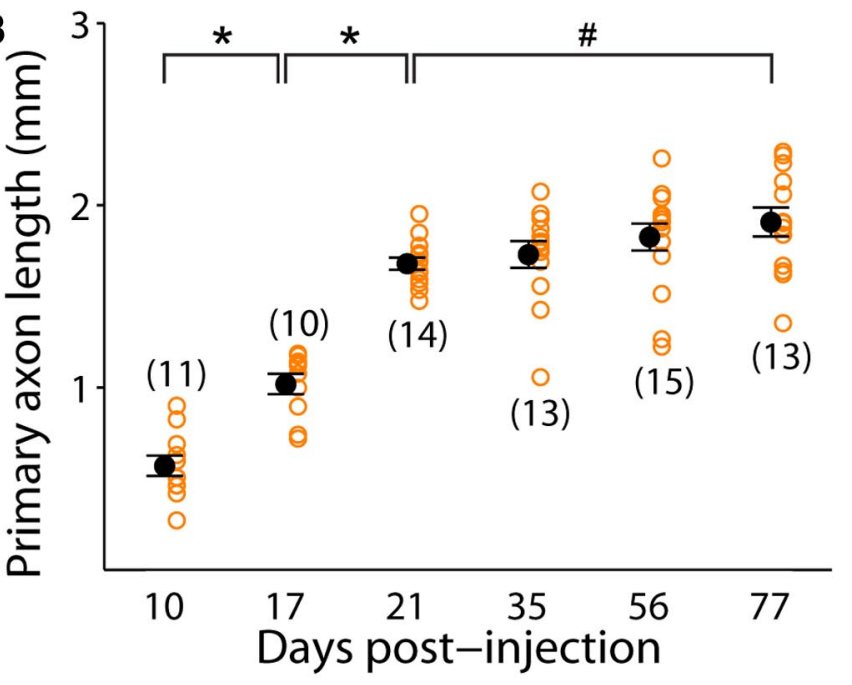

C
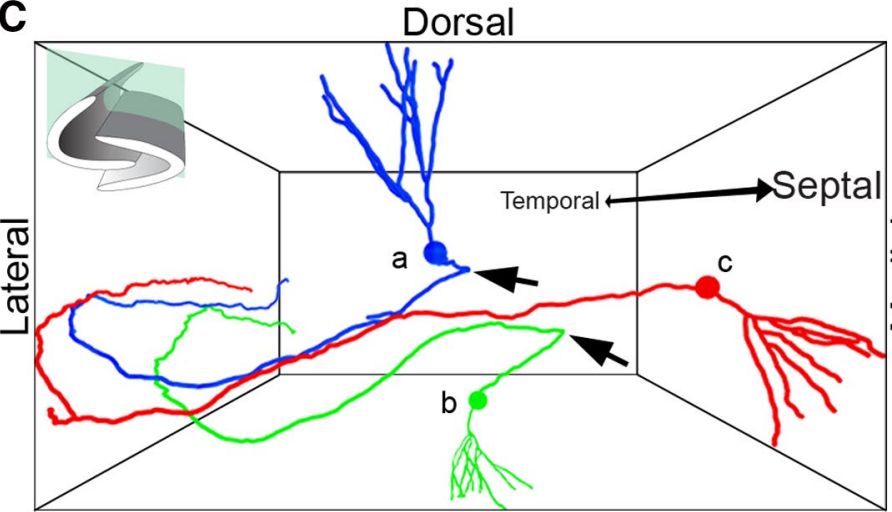

Ventral

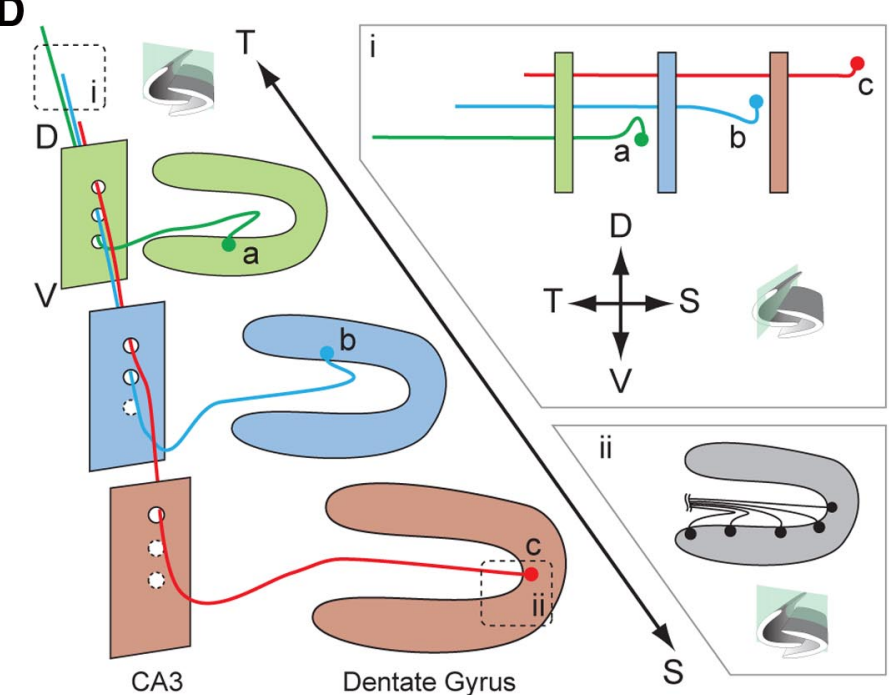

Figure 3. Axonal development, targeting, and organization of newborn granule cells in the adult mouse hippocampus. $A$, Horizontal view of sample traced axons from $10,17,21,35,56$, and 77 dpi. Scale bar, $100 \mu \mathrm{m}$. $\boldsymbol{B}$, Primary axon length of newborn granule neurons at different times after labeling. Open orange circles represent data from individual GFP ${ }^{+}$neurons examined. Numbers associated with open circles indicate total number of GFP ${ }^{+}$neurons examined for each condition. Values representing mean \pm SEM are also shown $\left({ }^{*} p<0.01\right.$; $\# p=0.12 ;$ one-way ANOVA, $\left.F_{(5,70)}=61.92, p \approx 0\right)$. C, Representative tracings of three adult-born granule cells with temporal (a), center (b), and septal (c) relative positions. Arrows highlight sharp turn of more laterally positioned granule cells. D. Coronal view and illustration of axon organization among adult-born granule cells in ( along the septo-temporal axis: (i) horizontal view illustrating axon stacking and staggering of termination points; (ii) coronal view illustrating graded axon hilar turns. T, temporal; S, septal; D, dorsal; $\mathrm{V}$, ventral.

gyrus granule cell layer. The initial hilar turn (Fig. $2 B$, \#1) was present in ever-increasing curvature from $0^{\circ}$ at the genu to $180^{\circ}$ at tips of the granule cell layer (Fig. $3 \mathrm{D}$, ii). Thus, axons originating from more lateral granule cells would first grow medially toward the genu before making an about-face turn toward CA3c. Together, these studies reveal a stereotypic organization between axons of adult-born neurons born around the same time and suggest an intricate axon guidance behavior during adult neurogenesis. 

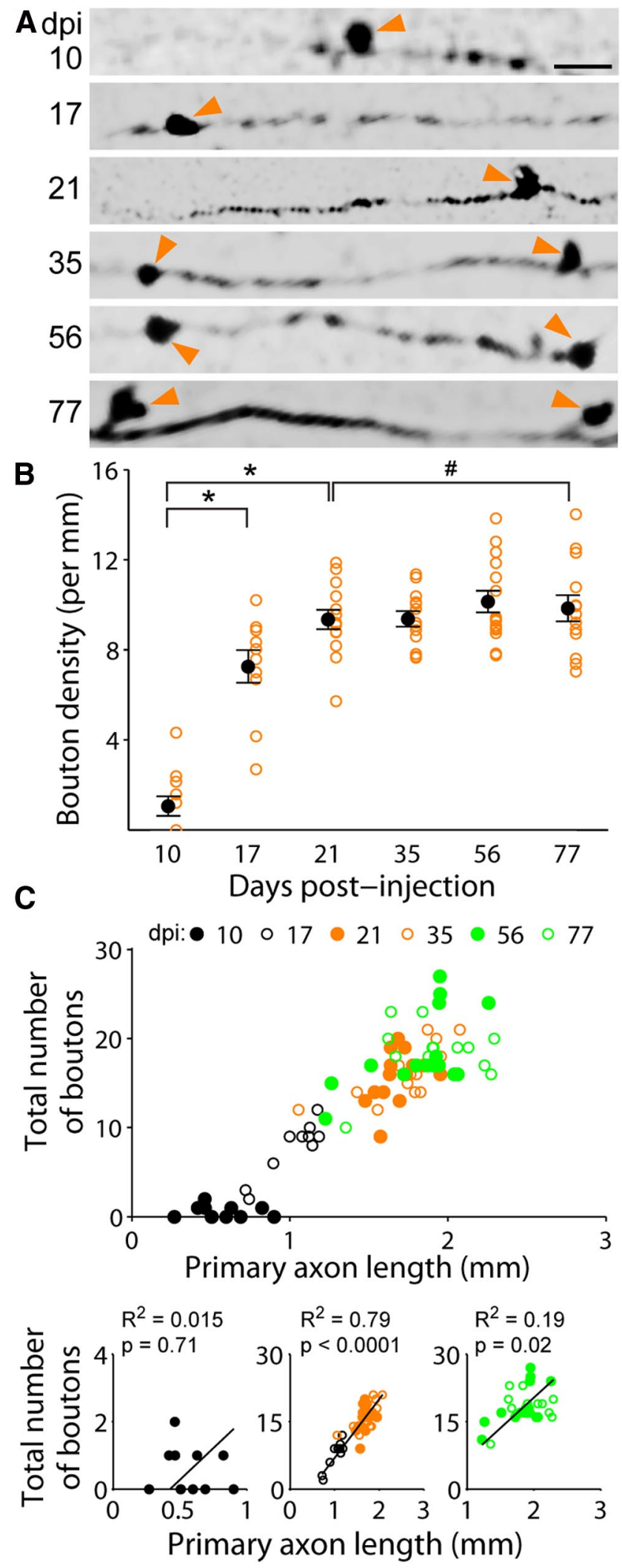

Figure 4. Axon bouton development of newborn granule cells in the adult mouse hippocampus. $\boldsymbol{A}$, Sample confocal images of axon segments within the CA3b ( $2 \mu \mathrm{m}$ depth). Arrows denote axon boutons. Scale bar, $10 \mu \mathrm{m}$. $\boldsymbol{B}$, Axonal mossy fiber bouton density of newborn granule neurons at different times after labeling. Open orange circles represent data from individual GFP ${ }^{+}$neurons examined (the same set of neurons as in Fig. 3). Values representing mean \pm SEM are also shown $\left({ }^{*} p<0.01 ; \# p=0.98\right.$; one-way ANOVA, $F_{(5,70)}=44.01, p \approx$ $0)$. C, Relationship between total number of axon boutons and primary axon length for individual
Axon bouton development of adult-born dentate granule cells Dentate granule cell axons are also known as mossy fibers because they make morphologically distinct, large ( $>3 \mu \mathrm{m}$ diameter) en passant synapses or boutons with targets in the hilus and CA3 regions (Henze et al., 2000). We focused our study on the development of these large mossy fiber boutons in the same previously analyzed (Fig. 3) set of $\mathrm{GFP}^{+}$neurons between 10 and 77 dpi (Fig. $4 A$ ). Similar to axonal development, we observed two phases of bouton development. At the population level, average bouton density increased dramatically from 10 to $21 \mathrm{dpi}$ and remained constant thereafter (21-77 dpi; Fig. 4B). To examine whether granule cell axons developed a constant number of boutons, or whether bouton numbers scaled directly with primary axon length, we quantified total bouton number and axon length at an individual cell level (Fig. 4C). At 10 dpi, boutons were mostly absent (Fig. $4 B$ ) and therefore uncorrelated with axon length $\left(R^{2}=0.02, p=0.71\right)$. Primary axon length correlated strongly with bouton number from 17 through $35 \mathrm{dpi}\left(R^{2}=0.79, p<\right.$ $0.0001)$. From 56 to $77 \mathrm{dpi}$, bouton numbers were weakly correlated with primary axon length $\left(R^{2}=0.19, p=0.02\right)$. Heterogeneity in both primary axon length and bouton numbers was most marked at 56 and 77 dpi (Fig. 4C). Such heterogeneity may have implications for how newborn granule cells choose and maintain synaptic partners in CA3 of the adult dentate gyrus.

Complete dendritic structure of adult-born granule cells and relationship to axonal development

SEBI also enables reconstruction of complete dendritic arbors without sectioning artifact; this allowed for the first fullstructure characterization of intact newborn granule cell dendritic development in the adult mouse hippocampus (Fig. 5A). Interestingly, and similar to axonal development, dendrites of newborn neurons exhibited a defined window of rapid growth. Consistent with previous characterizations of dendritic arbors from histological slices (Ge et al., 2006; Zhao et al., 2006), dendritic growth was most rapid and average total dendritic length more than doubled during an initial phase from 10 to $21 \mathrm{dpi}$ (Fig. 5B). The total number of dendritic branches peaked by $17 \mathrm{dpi}$ (Fig. $5 \mathrm{C}$ ). Sholl analysis revealed that dendritic complexity stabilized by the end of the first growth phase at $21 \mathrm{dpi}$ (Fig. 5D). Similar to that seen in axonal development, there appeared to be minimal growth of dendrites during the phase from 21 to $77 \mathrm{dpi}$ (Fig. 5B). By $77 \mathrm{dpi}$, the average total dendritic length was $\sim 1.5 \mathrm{~mm}$.

Our fully reconstructed axons and dendrites were from discrete cells during different developmental stages, thus our approach enabled investigation of potential correlations between axonal and dendritic development (Fig. 6A). As observed individually, both primary axons and total dendrites exhibited a rapid growth phase (10-21 dpi) followed by a phase of minimal growth (21-77 dpi). Interestingly, axon to dendrite length ratio of individual neurons fluctuated from high to low from 10 to $17 \mathrm{dpi}$ before stabilizing at a constant $\sim 6: 5$ ratio between 17 and $77 \mathrm{dpi}$ (Fig. 6A,B). We also calculated the growth rates of axons and dendrites for their two developmental phases (Fig. 6C). From 10 to $21 \mathrm{dpi}$, axon primary projections grew at a rate of $97 \pm 5.7 \mu \mathrm{m}$ per day (mean \pm SEM) and exhibited strong linear correlation

adult-born granule cells at different developmental stages. Top graph, Scatter plot of data from individual neurons (same set as in B). Bottom graphs, Individual plots for 10, 17-35, and $56-77$ dpi with linear fit and Pearson's correlation $R^{2}$ ( $p$ value from Student's $t$ test). 

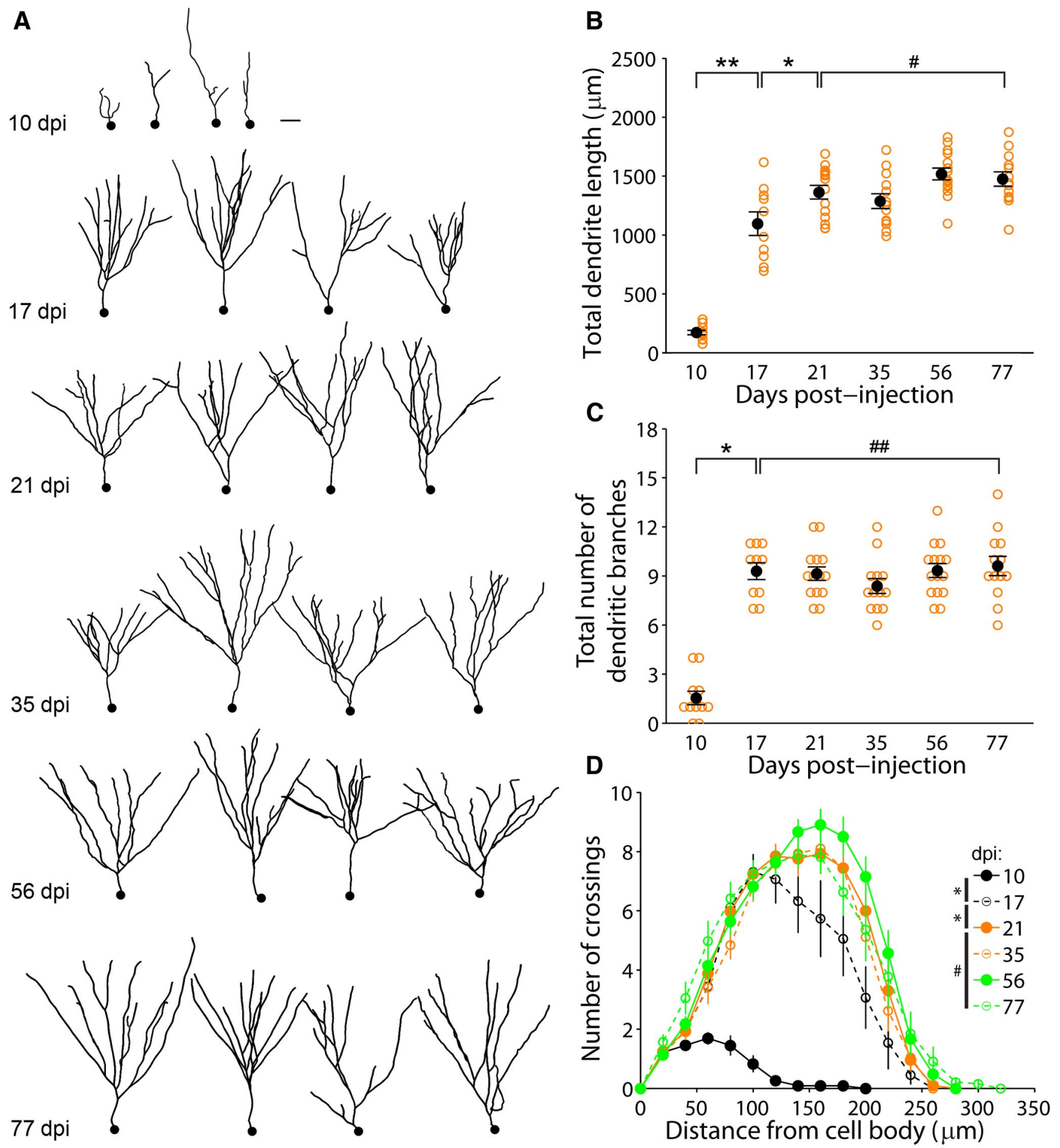

Figure 5. Dendritic development of newborn granule cells in the adult mouse hippocampus. $\boldsymbol{A}$, Sample 2D-projection tracings of complete dendritic processes of adult-born granule cells at different times after labeling. Scale, $30 \mu \mathrm{m}$. $\boldsymbol{B}, \boldsymbol{C}$, Total dendritic length $(\boldsymbol{B})$ and branch number $(\boldsymbol{C})$ of newborn granule neurons at different stages during adult hippocampal neurogenesis (same set of GFP ${ }^{+}$neurons as in Figs. 3, 4). Open orange circles represent data from individual GFP ${ }^{+}$neurons examined. Values representing mean \pm SEM are also shown $\left(\mathbf{O} ;{ }^{*} p<0.01 ;{ }^{* *} p<0.05\right.$; $\# p=0.76 ; \# \# \approx \approx$; ; one-way ANOVA, $\left.(\boldsymbol{B}) F_{(5,70)}=62.60, p \approx 0,(\boldsymbol{C}) F_{(5,70)}=39.29, p \approx 0\right)$. $\boldsymbol{D}$, Sholl analysis of dendritic complexity (the same set of neurons as in $\boldsymbol{B}$ and $\boldsymbol{C}$ ). Values represent mean \pm SEM $\left({ }^{*} p<0.05 ; \# p=0.68\right.$; two-sample Kolmogorov-Smirnov test).

with time $\left(R^{2}=0.931, p=0.17\right)$. The same analysis of dendrite growth from 10 to $21 \mathrm{dpi}$ also yielded strong correlation $\left(R^{2}=\right.$ $0.98, p=0.10)$, with a growth rate of $111 \pm 5 \mu \mathrm{m}$ per day. From these linear fits, axon growth would therefore begin $\sim 4.7 \mathrm{~d}(x-$ intercept) after new neurons were born, and dendrites would commence growth $\sim 8 \mathrm{~d}$ after their birth. Interestingly, although from 21 to 77 dpi newborn neurons appeared to show minimal change in their primary axon and total dendritic length, there were statistically significant and measureable growth rates for both primary axons $(4.1 \pm 1.5 \mu \mathrm{m})$ and dendrites $(3.2 \pm 1.3 \mu \mathrm{m}$ per day; Fig. 6C). Together, our individual cell analyses reveal for the first time how primary axon and whole dendrite outgrowth is coordinated at different developmental phases during adult hippocampal neurogenesis in vivo. 

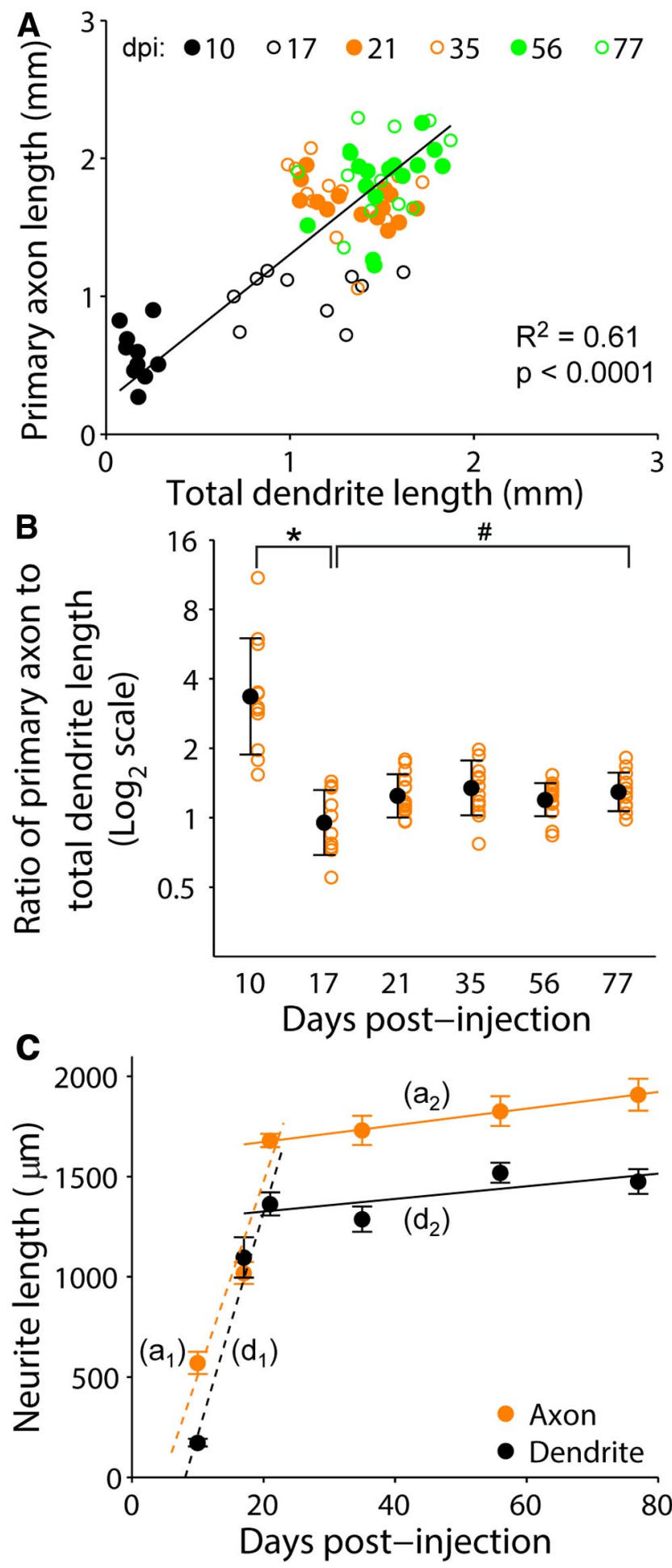

Figure 6. Relationship between axonal and dendritic development of individual newborn granule cells during adult hippocampal neurogenesis. $\boldsymbol{A}$, Scatter plot of primary axon and total dendritic length of individual adult-born granule cells examined for all time points (the same set of GFP ${ }^{+}$neurons as in Fig. 3). Also shown is a linear fit of data from 10 to $77 \mathrm{dpi}$ ( $y=1068 x+$ 235.7) with Pearson's correlation $R^{2}$ ( $p$ value from Student's $t$ test). $\boldsymbol{B}$, Ratio of primary axonal and total dendritic length of individual adult-born granule cells at different developmental stages (same set of neurons as in $\boldsymbol{A}$ ). 0 pen orange circles represent data from individual GFP ${ }^{+}$ neurons examined. Values representing mean \pm SD are also shown $\left(0 ;{ }^{*} p<0.01 ; \# p=0.98\right.$; one-way ANOVA, $F_{(5,70)}=12.47, p=1.16 \times 10^{-8}$ ). $C$, Mean neurite length (primary axon or total dendrite length) of adult-born granule cells at different times after labeling. The same data from Figs. $3 B$ and $5 B$ were replotted in the same graph for direct comparison of growth rates. Values represent mean $\pm S E M, a_{1}$, First phase axon growth rate linear fit (10-21 dpi):

\section{Discussion}

We have for the first time reconstructed the complete axonal primary projection and total dendritic structure of intact adultborn hippocampal dentate granule cells, and have identified their morphological characteristics and developmental milestones (Fig. 7). Our detailed morphological studies revealed that axons follow a stereotyped trajectory to their targets and exhibit a unique laminar architecture (Fig. 7A, 1-4), suggesting the existence of highly complex mechanisms of axon targeting within the adult brain. Our quantitative analysis at the individual cell level also revealed coordinated axonal and dendritic development of adult-born neurons during distinct developmental phases (Fig. $7 \mathrm{~B}, \mathrm{C}$ ). Our findings are particularly relevant for understanding the potential of this newborn population to influence downstream information processing in the CA3 region, an important parameter given many studies suggesting that newborn neurons make unique contributions to hippocampal function during a critical period of development (Ge et al., 2007; Aimone et al., 2011; Sahay et al., 2011; Gu et al., 2012; Marín-Burgin et al., 2012). Our findings also establish the basis for future studies of underlying molecular mechanisms and aberrant granule cell morphology in pathological conditions.

\section{Morphology and patterns of adult-born granule cell axons}

Individual adult-born neurons achieve stereotyped and highly complex axonal projections in the adult hippocampus via three distinct choice points (Fig. 7A, 1-3). First, axons turn various degrees in the dentate gyrus hilus depending on their parent soma location and converge in the stratum lucidum to join the mossy fiber pathway into CA3c (Fig. 7A, 1). The finding that axons of newborn neurons at the lateral-most granule cell layer can initiate outgrowth in a direction opposite to their ultimate trajectory suggests precisely positioned, finely tuned guidance cues in the hilus and $\mathrm{CA} 3 \mathrm{c}$ region to fasciculate these axons. Second, axons project from ventral to dorsal in the transverse plane of CA3b (Fig. 7A, 2). Previous studies of adult-born granule cell axonal development predominantly reported this segment (Zhao et al., 2006; Faulkner et al., 2008; Toni et al., 2008; Römer et al., 2011; Gu et al., 2012), which represents only $\sim 25 \%$ of the entire axonal CA3 projection length of mature adult-born granule cells. Last, axons turn to project longitudinally in CA3a toward the temporal hippocampal pole (Fig. 7A,3). This longitudinal projection accounts for $\sim 50 \%$ of primary axon length $(\sim 950 \mu \mathrm{m})$ and has historically been disputed. Work by Blackstad et al. (1970) proposed that only the transverse CA3 projection exists, whereas Ramón y Cajal (1893), Lorente de Nó (1934), and later McLardy $(1963,1970)$ suggested an additional longitudinal projection. Our results support more recent evidence of a longitudinal projection in dentate granule cells (Swanson et al., 1978; Tamamaki and Nojyo, 1991; Acsády et al., 1998; Hastings and Gould, 1999).

Our study revealed, for the first time, that cohorts of adultborn granule cells born around the same time organized their axons into highly stereotypic lamination patterns along the

$\leftarrow$

$y=96.8 x-458\left(p=3.5 \times 10^{-15} ; 95 \%\right.$ confidence interval: 84.1 to 113.5 and -728 to -228 for slope and $y$-intercept, respectively). $a_{2}$, Second phase axon growth rate linear fit: $y=$ $4.1 x+1591$ ( $p=0.01 ; 95 \%$ confidence interval: 0.99 to 7.29 and 1428 to 1753 for slope and $y$-intercept, respectively). $d_{1}$, First phase dendrite growth rate linear fit (10-21 dpi): $y=$ $111 x-896,\left(p=1.6 \times 10^{-14} ; 95 \%\right.$ confidence interval: 92.4 to 126.8 and -1177 to -592 for slope and $y$-intercept, respectively). $\mathrm{d}_{2}$, Second phase dendrite growth rate linear fit: $y=$ $3.2 x+1262(p=0.03 ; 95 \%$ confidence interval: 0.32 to 5.98 and 1120 to 1412 for slope and $y$-intercept, respectively). 

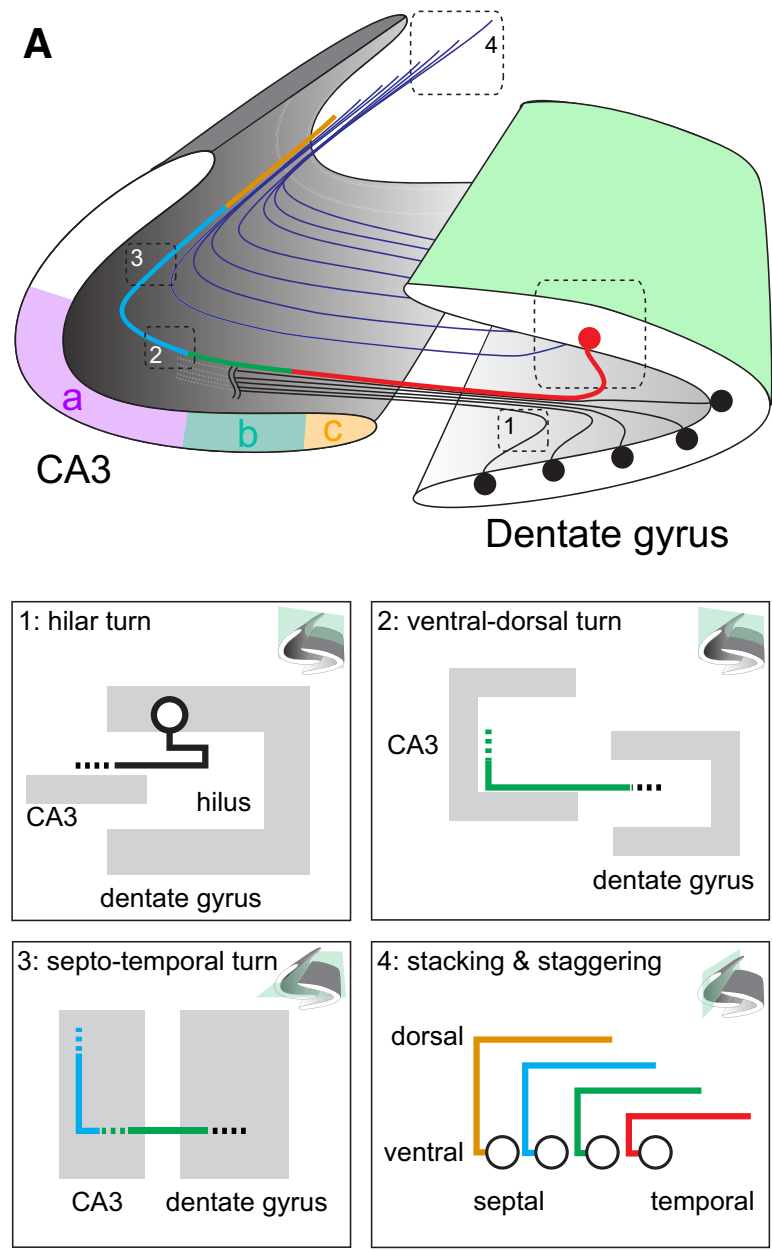
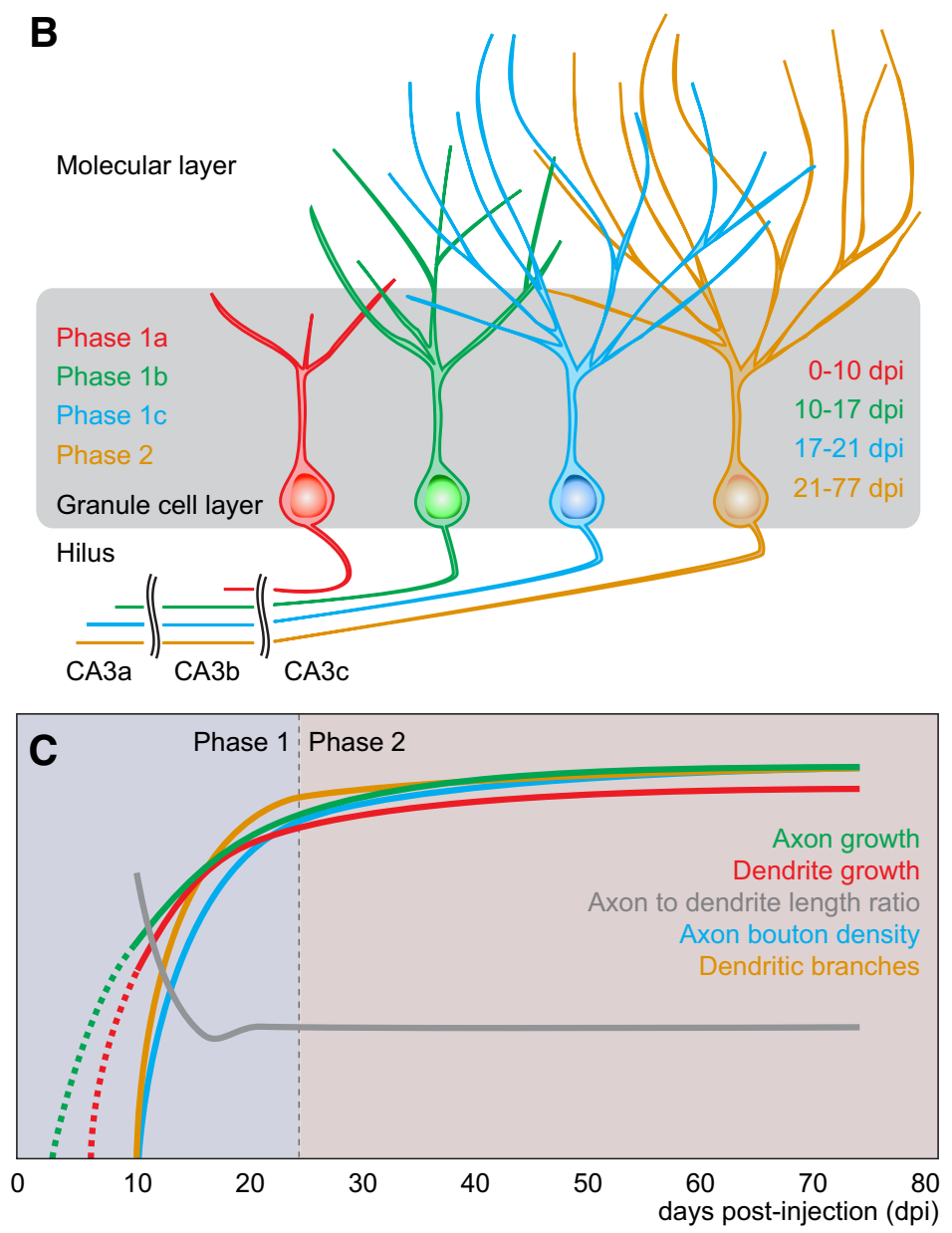

Figure 7. Summary of newborn granule cell axonal and dendritic morphological characteristics and development milestones during young adult mouse hippocampal neurogenesis. $A, 0$ verview of adult dentate gyrus and $\mathrm{CA} 3$ regions (subregions $\mathrm{CAa}-\mathrm{c}$ colored in purple, green, and orange, respectively) of the hippocampus with representative axon primary projection patterns overlaid. Boxed regions highlight important axon trajectory features and patterns: (1) characteristic $0-180^{\circ}$ hilar axon turn, as viewed in the transverse plane; (2) characteristic $90^{\circ}$ ventral to dorsal CA3 turn, as viewed in the transverse plane; (3) characteristic $90^{\circ}$ septal to temporal CA3 turn, as viewed in the horizontal (longitudinal) plane; (4) characteristic dorsal stacking of axons originating from more septal dentate gyrus and staggering of axon termination points, as viewed in a sagittal plane with respect to the hippocampal axis. $\boldsymbol{B}$, Schematic depiction of axon and dendrite development of adult-born granule neurons. Representative granule cells are color-coded according to their phase of structural development. Development is divided into two phases. Phase 1 is further subdivided on the basis of key morphological changes: 1a corresponds to rapid axon, but limited dendrite growth; $1 \mathrm{~b}$ corresponds to rapid dendrite growth and axon targeting through all CA3 subregions; and $1 \mathrm{c}$ corresponds to complete axo-dendritic targeting. Phase 2 is characterized by minimal growth of existing axonal and dendritic structures. C, Time course of axonal and dendritic development of adult-born granule neurons. Most growth and changes occur during phase 1 when axon and dendrite growth is maximal; axon to dendrite length ratio starts high and then rapidly decreases and stabilizes; and dendrite branching and axon bouton density rapidly increase. Very modest growth of axon primary projections and dendrites occurs during phase 2 .

septo-temporal axis (Fig. 7A, 4). More septal granule cells terminate their longitudinal projections earlier and more dorsal than those from more temporal regions, resulting in a precise stacking and staggering of axons within CA3a. Such exquisitely regular architecture exists, at least in adult-born neurons, throughout the septo-temporal extent of the hippocampus, in contrast to a previous study that suggested longitudinally projecting granule cell axons primarily existed in the septal, but not temporal hippocampal region (Swanson et al., 1978).

Functionally, since multiple longitudinally projecting granule cell axons are coincident in the same CA3a transverse plane, it is likely that CA3a pyramidal cells receive inputs from multiple dentate granule cells originating from different septo-temporal regions. In contrast, $\mathrm{CA} 3 \mathrm{~b}$ and CA3c pyramidal cells may receive inputs from multiple dentate granule cells of the same transverse plane. This organizational structure suggests that CA 3 has at least two distinct domains, in which neurons may perform different computations based upon mossy fiber input. Furthermore, axon stacking implies that, for a given CA3a pyramidal cell, axons from more septal granule cells are more proximal to CA3a neuron somas, potentially wielding more control than their temporal counterparts during integration of synaptic inputs. In all, our findings illustrate the previously underappreciated complexity of adult-born granule cell connections to CA3. This may inform our understanding of the role newborn neurons play in the hippocampal circuit and further suggest a new framework to explore the anatomical and functional relationship between the dentate gyrus and CA3.

\section{Distinct phases of axonal and dendritic development by adult-born granule cells}

We identified two phases of axonal and dendritic development within which key developmental milestones occur. Phase 1 is characterized by rapid neurite outgrowth $(0-21 \mathrm{dpi})$, which decelerates drastically in phase 2 . As dendritic growth has been characterized previously (Zhao et al., 2006), our current study focused on axon developmental milestones. 
Phase 1a, corresponding to $0-10 \mathrm{dpi}$, is marked by rapid axon penetration through CA3c into CA3b (Fig. 7B). Mossy fiber boutons are mostly absent at this stage. Our result is consistent with the finding that newborn neurons are unable to elicit CA3 pyramidal cell responses at this stage ( $\mathrm{Gu}$ et al., 2012), despite the presence of functional synaptic inputs (Espósito et al., 2005; Ge et al., 2006). In phase $1 \mathrm{~b}(10-17 \mathrm{dpi})$, axons penetrate CA3a and start to form mossy fiber boutons, which is consistent with previous electron microscopic results (Faulkner et al., 2008) and recent electrophysiological findings ( $\mathrm{Gu}$ et al., 2012). Interestingly, phase $1 \mathrm{~b}$ axons project minimally along the longitudinal axis of CA3a. Pyramidal cells from the same transverse plane are thus the predominant recipients of initial synaptic input, which limits the impact of adult-born granule cells on existing circuitry at this stage. In phase $1 \mathrm{c}(17-21 \mathrm{dpi})$, axon outgrowth continues and axons possess all morphological hallmarks of mossy fibers (Fig. 7A, 1-3) and reach maximum bouton density by 21 dpi.

Phase 2 (21-77 dpi) represents a very modest, but continued growth phase for both primary axons and whole dendrites of adult-born neurons. Our results underestimate the total amount of axonal growth due to our exclusion of axon collaterals. It is possible that axon collaterals exhibit different growth properties than the primary axon. Given the numerous collaterals and synaptic contacts of granule cells in the hilar region (Claiborne et al., 1986), future studies of newborn granule cell axon collateral development and growth dynamics using a sparse labeling approach would be fruitful and may reveal additional intricacies of axon targeting, maturation, and synaptic development.

\section{Coordination of axonal and dendritic development during adult neurogenesis}

Our reconstruction of neuronal processes of intact individual neurons revealed how axons and dendrites coordinate their development, which has been rarely examined in vivo. Quantitative analysis revealed that axon growth most likely preceded that of dendrites by $\sim 3.3 \mathrm{~d}$ (phase 1a; Figs. $6 B, C, 7 C$ ). At the onset of concurrent, rapid axonal and dendritic outgrowth (phase $1 b)$, the numbers of mossy fiber boutons and dendritic branch points increase $\sim 4$-fold. Dendritic spines have been previously shown to appear rapidly during the same period (Zhao et al., 2006). Both afferent perforant path and efferent $\mathrm{CA} 3$ responses can be elicited during phase 1b (Ge et al., 2006; Gu et al., 2012). Axonal and dendritic development coupling may therefore allow for coincident onset of presynaptic and postsynaptic responses that aid functional integration of newborn neurons into the existing hippocampal circuit.

\section{SEBI methodology and considerations}

Our development and application of the novel SEBI technique for seamless, complete hippocampal volume reconstruction was essential for detailed morphological and developmental characterization of adult-born granule cells. In contrast to a similar technique (Ragan et al., 2012), SEBI uses hardware and software readily available in most lab settings and thus can be widely applied. More recently, novel tissue-clearing techniques have been developed (Hama et al., 2011; Chung et al., 2013; Kuwajima et al., 2013), which allow for limitless imaging through tissue. Given working distance limitations of most microscope objectives, SEBI may still be required in conjunction and is fully compatible with tissue clearing. In addition, SEBI yields serial brain sections amenable for further post hoc analyses, including immunohistology and electron microscopy.

\section{Conclusion}

Using the SEBI methodology, we have revealed the complete axonal primary projection and total dendritic structure of intact adult-born hippocampal dentate granule cells in vivo. We identified highly stereotyped patterns of axonal development at the individual cell level and among neurons born around the same time. These findings, coupled with new insights into dendritic development, suggest a tightly regulated growth and targeting process during adult neurogenesis. Our comprehensive data provide the foundation for future studies to determine how this complicated process is regulated at the molecular level, whether anatomical or morphological disruptions occur in neurological disorders, and whether embryonic versus adult granule cell development may differ. Importantly, our studies have demonstrated that an adult brain region, the hippocampus, can support intricate guidance of long axonal projections. Accurate axonal targeting in the adult brain is a critical challenge for cell transplantation therapy to treat neurological disease and injury and the adult hippocampus could thus serve as a model system to explore the necessary and sufficient factors.

\section{References}

Acsády L, Kamondi A, Sík A, Freund T, Buzsáki G (1998) GABAergic cells are the major postsynaptic targets of mossy fibers in the rat hippocampus. J Neurosci 18:3386-3403. Medline

Aimone JB, Deng W, Gage FH (2011) Resolving new memories: a critical look at the dentate gyrus, adult neurogenesis, and pattern separation. Neuron 70:589-596. CrossRef Medline

Blackstad TW, Brink K, Hem J, Jeune B (1970) Distribution of hippocampal mossy fibers in the rat. An experimental study with silver impregnation methods. J Comp Neurol 138:433-449. CrossRef Medline

Bolstad BM, Irizarry RA, Astrand M, Speed TP (2003) A comparison of normalization methods for high density oligonucleotide array data based on variance and bias. Bioinformatics 19:185-193. CrossRef Medline

Bonaguidi MA, Song J, Ming GL, Song H (2012) A unifying hypothesis on mammalian neural stem cell properties in the adult hippocampus. Curr Opin Neurobiol 22:754-761. CrossRef Medline

Chung K, Wallace J, Kim SY, Kalyanasundaram S, Andalman AS, Davidson TJ, Mirzabekov JJ, Zalocusky KA, Mattis J, Denisin AK, Pak S, Bernstein H, Ramakrishnan C, Grosenick L, Gradinaru V, Deisseroth K (2013) Structural and molecular interrogation of intact biological systems. Nature 497:332-337. CrossRef Medline

Claiborne BJ, Amaral DG, Cowan WM (1986) A light and electron microscopic analysis of the mossy fibers of the rat dentate gyrus. J Comp Neurol 246:435-458. CrossRef Medline

Duan X, Chang JH, Ge S, Faulkner RL, Kim JY, Kitabatake Y, Liu XB, Yang CH, Jordan JD, Ma DK, Liu CY, Ganesan S, Cheng HJ, Ming GL, Lu B, Song H (2007) Disrupted-In-Schizophrenia 1 regulates integration of newly generated neurons in the adult brain. Cell 130:1146-1158. CrossRef Medline

Emmenlauer M, Ronneberger O, Ponti A, Schwarb P, Griffa A, Filippi A, Nitschke R, Driever W, Burkhardt H (2009) XuvTools: free, fast and reliable stitching of large 3D datasets. J Microsc 233:42-60. CrossRef Medline

Espósito MS, Piatti VC, Laplagne DA, Morgenstern NA, Ferrari CC, Pitossi FJ, Schinder AF (2005) Neuronal differentiation in the adult hippocampus recapitulates embryonic development. J Neurosci 25:10074-10086. CrossRef Medline

Faulkner RL, Jang MH, Liu XB, Duan X, Sailor KA, Kim JY, Ge S, Jones EG, Ming GL, Song H, Cheng HJ (2008) Development of hippocampal mossy fiber synaptic outputs by new neurons in the adult brain. Proc Natl Acad Sci U S A 105:14157-14162. CrossRef Medline

Ge S, Goh EL, Sailor KA, Kitabatake Y, Ming GL, Song H (2006) GABA regulates synaptic integration of newly generated neurons in the adult brain. Nature 439:589-593. CrossRef Medline

Ge S, Yang CH, Hsu KS, Ming GL, Song H (2007) A critical period for enhanced synaptic plasticity in newly generated neurons of the adult brain. Neuron 54:559-566. CrossRef Medline

Gu Y, Arruda-Carvalho M, Wang J, Janoschka SR, Josselyn SA, Frankland 
PW, Ge S (2012) Optical controlling reveals time-dependent roles for adult-born dentate granule cells. Nat Neurosci 15:1700-1706. CrossRef Medline

Hama H, Kurokawa H, Kawano H, Ando R, Shimogori T, Noda H, Fukami K, Sakaue-Sawano A, Miyawaki A (2011) Scale: a chemical approach for fluorescence imaging and reconstruction of transparent mouse brain. Nat Neurosci 14:1481-1488. CrossRef Medline

Hastings NB, Gould E (1999) Rapid extension of axons into the CA3 region by adult-generated granule cells. J Comp Neurol 413:146-154. CrossRef Medline

Henze DA, Urban NN, Barrionuevo G (2000) The multifarious hippocampal mossy fiber pathway: a review. Neuroscience 98:407-427. CrossRef Medline

Kim JY, Liu CY, Zhang F, Duan X, Wen Z, Song J, Feighery E, Lu B, Rujescu D, St Clair D, Christian K, Callicott JH, Weinberger DR, Song H, Ming GL (2012) Interplay between DISC1 and GABA signaling regulates neurogenesis in mice and risk for schizophrenia. Cell 148:1051-1064. CrossRef Medline

Kron MM, Zhang H, Parent JM (2010) The developmental stage of dentate granule cells dictates their contribution to seizure-induced plasticity. J Neurosci 30:2051-2059. CrossRef Medline

Kuwajima T, Sitko AA, Bhansali P, Jurgens C, Guido W, Mason C (2013) ClearT: a detergent- and solvent-free clearing method for neuronal and non-neuronal tissue. Development 140:1364-1368. CrossRef Medline

Lorente de Nó R (1934) Studies on the structure of the cerebral cortex. II. Continuation of the study of the ammonic system. J Psychol Neurol 45:381-438

Luzzati F, Fasolo A, Peretto P (2011) Combining confocal laser scanning microscopy with serial section reconstruction in the study of adult neurogenesis. Front Neurosci 5:70. Medline

Marín-Burgin A, Mongiat LA, Pardi MB, Schinder AF (2012) Unique processing during a period of high excitation/inhibition balance in adultborn neurons. Science 335:1238-1242. CrossRef Medline

Markakis EA, Gage FH (1999) Adult-generated neurons in the dentate gyrus send axonal projections to field CA3 and are surrounded by synaptic vesicles. J Comp Neurol 406:449-460. CrossRef Medline

McLardy T (1963) Some cells and fiber peculiarities of uncal hippocampus. Progr Brain Res 3:71-88. CrossRef

McLardy T, Kilmer WL (1970) Hippocampal circuitry. Am Psychol 25:563566. CrossRef Medline
Ming GL, Song H (2011) Adult neurogenesis in the mammalian brain: significant answers and significant questions. Neuron 70:687-702. CrossRef Medline

Piatti VC, Davies-Sala MG, Espósito MS, Mongiat LA, Trinchero MF, Schinder AF (2011) The timing for neuronal maturation in the adult hippocampus is modulated by local network activity. J Neurosci 31:77157728. CrossRef Medline

Ragan T, Kadiri LR, Venkataraju KU, Bahlmann K, Sutin J, Taranda J, Arganda-Carreras I, Kim Y, Seung HS, Osten P (2012) Serial twophoton tomography for automated ex vivo mouse brain imaging. Nat Methods.

Ramón y Cajal S (1893) Estructura del asta de Ammon fascia dentata. Am Soc Esp Hist Nat 22:53-114.

Römer B, Krebs J, Overall RW, Fabel K, Babu H, Overstreet-Wadiche L, Brandt MD, Williams RW, Jessberger S, Kempermann G (2011) Adult hippocampal neurogenesis and plasticity in the infrapyramidal bundle of the mossy fiber projection: I. Co-regulation by activity. Front Neurosci 5:107. Medline

Sahay A, Wilson DA, Hen R (2011) Pattern separation: a common function for new neurons in hippocampus and olfactory bulb. Neuron 70:582-588. CrossRef Medline

Swanson LW, Wyss JM, Cowan WM (1978) An autoradiographic study of the organization of intrahippocampal association pathways in the rat. J Comp Neurol 181:681-715. CrossRef Medline

Tamamaki N, Nojyo Y (1991) Crossing fiber arrays in the rat hippocampus as demonstrated by three-dimensional reconstruction. J Comp Neurol 303:435-442. CrossRef Medline

Tessier-Lavigne M, Goodman CS (1996) The molecular biology of axon guidance. Science 274:1123-1133. CrossRef Medline

Toni N, Laplagne DA, Zhao C, Lombardi G, Ribak CE, Gage FH, Schinder AF (2008) Neurons born in the adult dentate gyrus form functional synapses with target cells. Nat Neurosci 11:901-907. CrossRef Medline

Zhao C, Teng EM, Summers RG Jr, Ming GL, Gage FH (2006) Distinct morphological stages of dentate granule neuron maturation in the adult mouse hippocampus. J Neurosci 26:3-11. CrossRef Medline

Zhou M, Li W, Huang S, Song J, Kim JY, Tian X, Kang E, Sano Y, Liu C, Balaji J, Wu S, Zhou Y, Zhou Y, Parivash SN, Ehninger D, He L, Song H, Ming GL, Silva AJ (2013) mTOR inhibition ameliorates cognitive and affective deficits caused by Discl knockdown in adult-born dentate granule neurons. Neuron 77:647-654. CrossRef Medline 